\title{
Noble gas geochemistry in the Wufeng-Longmaxi shale of the southern Sichuan Basin, China
}

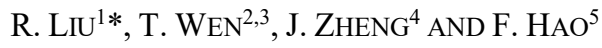

${ }^{1}$ Southwest Petroleum Univ., Chengdu 610500, China

(*correspondence: liurui@outlook.com)

${ }^{2}$ Penn State University, University Park, PA 16801, USA

${ }^{3}$ Syracuse University, Syracuse, NY 13244, USA

${ }^{4}$ Sichuan Changning Natural Gas Development LLC, Chengdu 610051, China

${ }^{5}$ China University of Petroleum, Qingdao 266580, China

The global energy landscape has experienced substantial changes due to the rapid development of unconventional (e.g., shale plays) oil/gas production in the last two decades. The charaterization of organic-rich black shale and the associated total petroleum system is particularly important to i) guide the future acitivies of hydrocarbon exploration and production acitivies, ii) assess the potential environmental impacts on the critical zone, and iii) shed light on the geological and thermal history of the sedimentary basin of interest. Noble gases are inert and stable rendering them ideal tracers to characterize shale composition, and track the origin and migration of fluids. As one of the most prolific petroleum basins in the world, the Sichuan Basin in China has only been studied in few cases for its noble gas composition.

We collected 24 samples from 12 production gas wells tapping the Wufeng-Longmaxi shale at different depths located in the southern Sichuan Basin for the analyses of a complete set of noble gases ( $\mathrm{He}, \mathrm{Ne}, \mathrm{Ar}, \mathrm{Kr}, \mathrm{Xe}$ ), bulk gas composition, and stable isotopes of hydrocarbons. Previously reported noble gas data from the Wufeng-Longmaxi and other shales are compiled annd compared with our data in order to delineat the origin, migration, and mixing processes of fluids in shales.

Preliminary results show consistently crustal-like ${ }^{3} \mathrm{He} /{ }^{4} \mathrm{He}$ ratio $\sim 0.01 \mathrm{Ra}$ ( $\mathrm{Ra}={ }^{3} \mathrm{He} /{ }^{4} \mathrm{He}$ ratio of air) throughout the Wufeng-Longmaxi shale indicating that collected samples were well perserved. ${ }^{20} \mathrm{Ne} /{ }^{22} \mathrm{Ne}$ and ${ }^{21} \mathrm{Ne} /{ }^{22} \mathrm{Ne}$ ratios range from 9.59 to 9.97 and from 2.48 to $4.18 \times 10^{-2}$, while ${ }^{40} \mathrm{Ar} /{ }^{36} \mathrm{Ar}$ values vary from 458.4 to 1360.4 , much higher than the corresponding air value of 295.5 suggesting dominant crustal $\mathrm{Ar}$ endmember. ${ }^{86} \mathrm{Kr} /{ }^{84} \mathrm{Kr}$ and ${ }^{136} \mathrm{Xe} /{ }^{130} \mathrm{Xe}$ ratios are close to corresponding air values. Calculated ${ }^{20} \mathrm{Ne} /{ }^{36} \mathrm{Ar}$ and ${ }^{4} \mathrm{He} /{ }^{40} \mathrm{Ar} *$ ratios display a dichotomy between samples from deep-buried depression and shallow-buried crest. The discrepany in noble gas signatures suggests that WufengLongmaxi shale is compartmentalized with disctint evolution history of fluid and heat in different parts of the shale. 